\title{
Nature and extent of histological changes induced by argon laser photocoagulation in canine gastric
} mucosa

\author{
D F KELLY,* S G BOWN $\dagger$, P R SALMON, B M CALDER, H PEARSON, AND \\ B M Q WEAVER
}

From the Departments of Pathology, Medicine and Veterinary Surgery, University of Bristol, Bristol

SUMMARY The tissue changes in canine gastric mucosa caused by exposure to an argon laser beam vary from mild mucosal oedema to complete cell destruction. Intermediate degrees of damage cause an inflammatory cell response with the formation of granulation tissue, particularly in the submucosa. The rate of healing is similar to that after other forms of injury to the gastric mucosa. Cell destruction at the surface of the mucosa starts with energies greater than 8 Joules on any one spot, and occurs at greater depths as the energy is increased but, unless cells are actually destroyed, the extent of histological damage is limited to a zone $1 \mathrm{~mm}$ lateral to, or below, the area exposed to the laser beam. Haemostasis is achieved by thermal contraction of bleeding vessels and of the surrounding tissue, thrombosis only occurring as a secondary effect.

When a new therapeutic method is introduced, it is essential to establish under which circumstances it is applicable, and the nature and extent of any hazardous side-effects. We described previously the factors which determine the extent of tissue damage produced by the argon laser and those which determine its effectiveness for photocoagulation. ${ }^{1}$ In this paper, we describe the histological nature of the changes produced experimentally in the stomach wall a few minutes after exposure to the laser, and after one, two, and four weeks. Previous publications ${ }^{23}$ have described some of these changes, but we extend the discussion to relate the nature and extent of the changes seen to the area exposed to the laser beam, the energy deposited in the tissue, and the mechanism of haemostasis.

\section{Methods}

We used a Spectra Physics 171 argon ion laser, which provides an output of up to $15 \mathrm{~W}$ continuous

\footnotetext{
*Present address: Department of Veterinary Pathology, University of Liverpool, PO Box 147, Liverpool L69 3BX.

+Present address and for correspondence: Dr S G Bown, The Rayne Institute, University College Hospital Medical School, 5 University Street, London WC1E 6JJ.

¥Present address: The Rayne Institute, University College Hospital Medical School, 5 University Street, London WC1E 6JJ.

Received for publication 29 July 1980
}

wave in the blue-green region of the visible spectrum. This was coupled to a single $200 \mu$ quartz fibre. The distal half of this fibre was fixed in a $2 \mathrm{~mm}$ Teflon catheter, so that a stream of $\mathrm{CO}_{2}$ gas could be used coaxial to the laser beam, to clear blood from a bleeding point before photocoagulation.

Experiments were carried out on 10 Beagle dogs. Their ages were between 10 and 18 months, they weighed 8-13 kg, and both sexes were used.

All studies were performed by laparotomy under a balanced general anaesthetic protocol, analgesic administration being continued into the postoperative period in recovery experiments.

The stomach was opened along the greater curvature and experiments carried out on the exposed gastric mucosa under direct vision. Initial studies on the effect of the laser on normal tissue were performed by creating lesions on intact mucosa varying the laser power, time of exposure, and the distance between the fibre tip and the mucosa. Haemostasis studies were carried out by creating ulcers in the stomach using the Quinton ulcer maker $^{2}$ in heparinised animals. These ulcers were then treated with the laser to assess its effectiveness at different powers. All laser lesions on intact mucosa, laser-treated ulcers, and untreated control ulcers were identified by suture markers for later histological examination. 


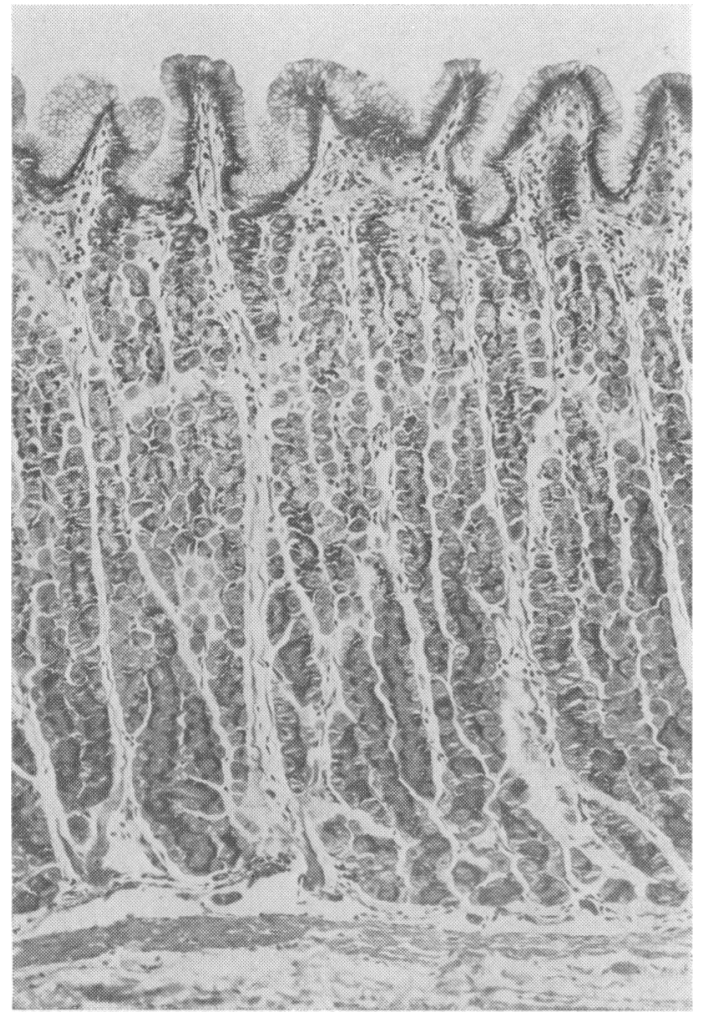

Fig. 1 Normal canine gastric mucosa. Haematoxylin and eosin. $H$ and $E, \times 128$. (Original magnifications quoted in this and succeeding figures.)

In acute studies, the animals were killed without regaining consciousness by increasing the dose of anaesthetic agents at the end of the procedure. In chronic studies, the stomach and abdominal wall were closed under sterile conditions and the animal allowed to recover until the necessary number of days had passed, when they were killed. Full details of the experimental procedure used have been published previously. ${ }^{1}$ At necropsy, stomachs were removed and opened, usually along the greater curvature, washed gently in cold water to remove excess mucus, pinned on a polystyrene board, and fixed in $10 \%$ formalin. After immersion in fixative for several days the treated parts of the stomach were dissected out and fixed separately for three to five days. Each treatment site was identified separately in fixative. Each site was trimmed into blocks (less than $1 \mathrm{~mm}$ thick) and fixed for an additional two days. Blocks were cut vertical to the surface of the mucosa and a wide margin of untreated mucosa was included in each block. Up to nine blocks of tissue were examined from each treatment site. Tissue blocks were fixed for several more days before paraffin-embedding. Sections were cut at $6 \mu$ and stained by the haematoxylin and eosin, Weigert's elastic-Van Gieson, and Martius Scarlet Blue techniques. $^{3}$

\section{GLOSSARY OF DESCRIPTIVE TERMS APPLIED TO GASTRIC LESIONS}

Many of the changes observed in the wall of the stomach after experimental ulceration or laser photocoagulation recur frequently in the following studies. To minimise repetition of descriptive detail, this section describes and illustrates the basic pathological changes to which later reference is made. Normal canine gastric mucosa is illustrated in Fig. 1.

\section{DEGENERATIVE CHANGES}

\section{Detachment of surface epithelium}

This is characterised by wrinkling of the layer of surface epithelium. The cells are swollen, but are still recognisable. There is often a longitudinal cleft between the detaching epithelium and the underlying lamina propria (Fig. 2).

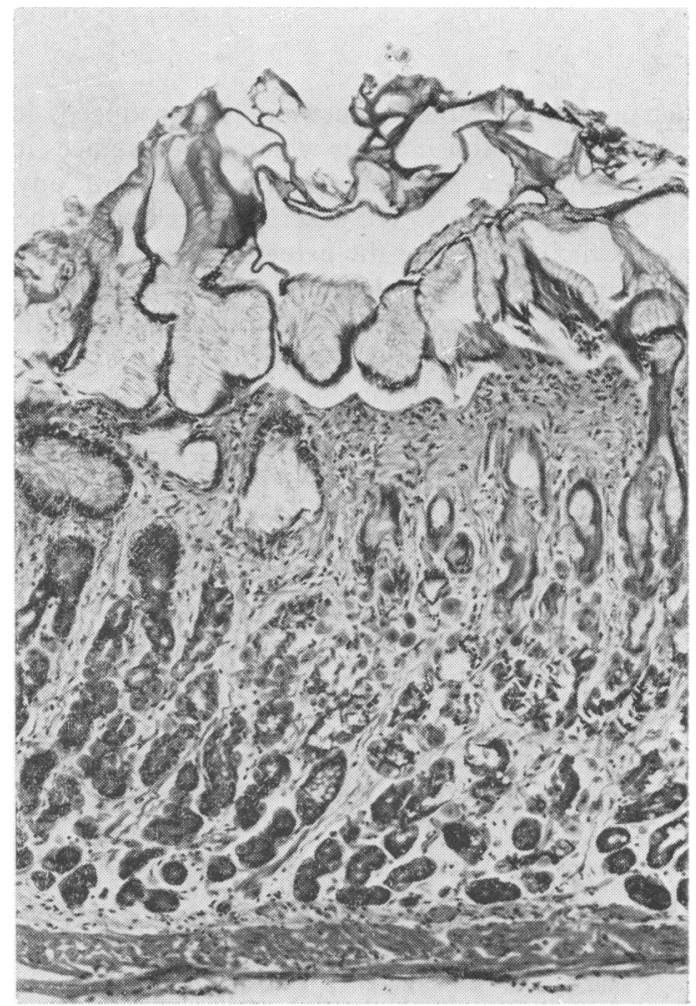

Fig. 2 Acute laser injury with detachment of surface epithelium. $H$ and $E, \times 128$. 
Fig. 3 Acute laser injury $(8 \mathrm{~W}, 1 \mathrm{~s})$. Mild damage to mucosa and submucosal connective tissue (arrows). The loose connective tissue outside the ellipse of damage appears normal. $H$ and $E, \times 50$.

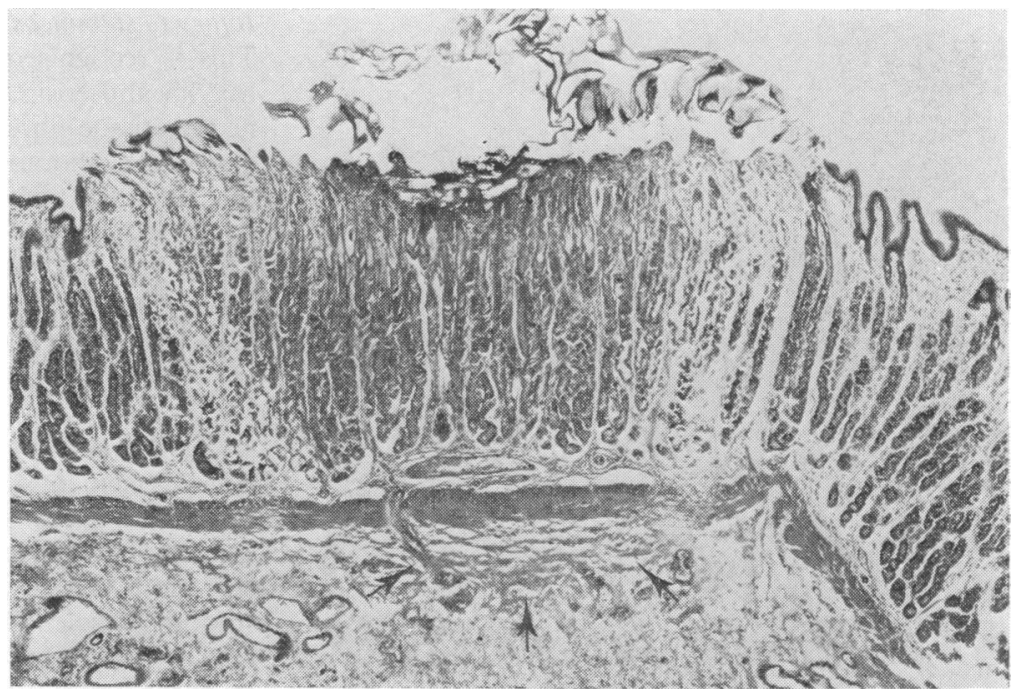

In situ mucosal damage

This is usually associated with detachment of surface epithelium. Beneath this is a zone of altered mucosa in which the epithelial cells are shrunken, stain less strongly, and have reduced nuclear/cytoplasmic staining contrast (Fig. 3).

\section{Mucosal erosion and ulceration}

These are characterised by loss of epithelium and lamina propria. This can vary in width and depth so that the lesion may extend into the muscularis mucosae, submucosa, or external muscle layers.
Usually the crater of an ulcer treated with the laser is covered in places by brown-black charred tissue (Fig. 4).

\section{Damage to smooth muscle}

Damage to muscularis mucosae or external muscle layer is recognised by decreased staining intensity and reduced nuclear/cytoplasmic contrast similar to that seen in the mucosa (Fig. 3 ). In more severe damage there is a defect in the muscularis mucosae with a loss of smooth muscle fibres.
Fig. 4 Laser treatment of induced ulcer (acute). Beneath the charred surface is a wide band of damaged submucosal connective tissue at the edge of the treated ulcer (arrows). $\boldsymbol{H}$ and $E, \times 50$.

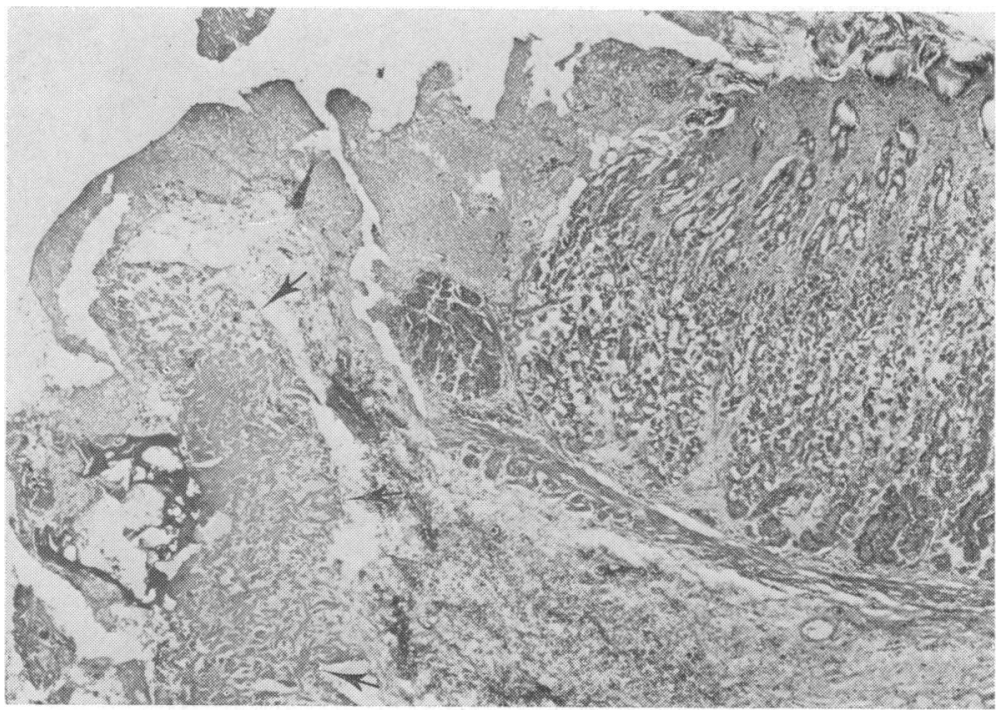




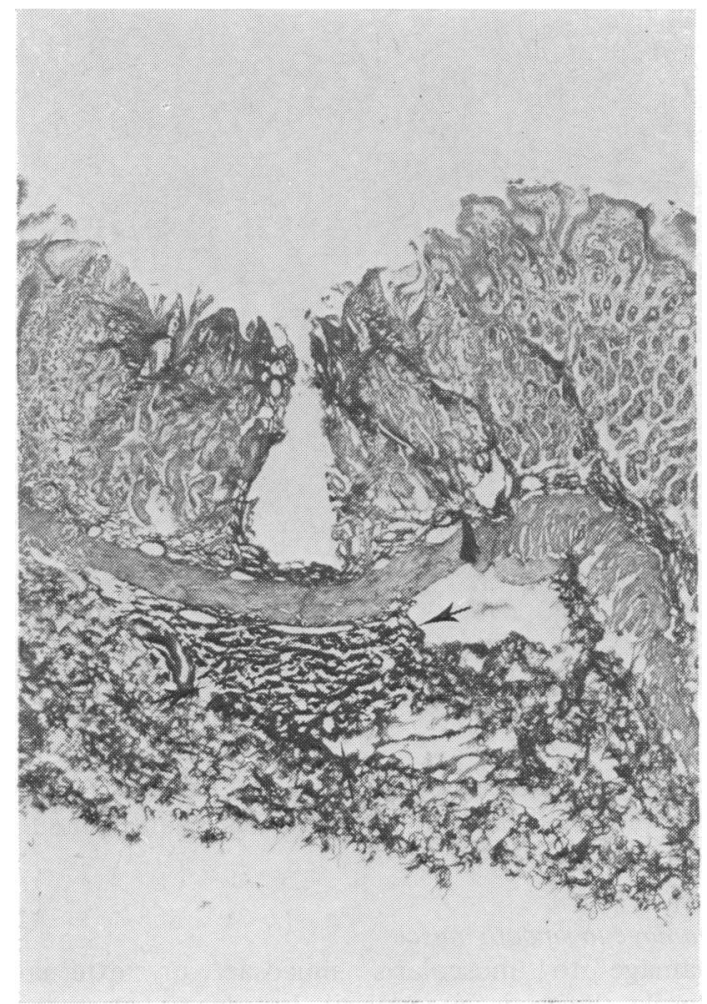

Fig. 5 Acute laser injury. Flask-shaped lesion with submucosal connective tissue 'burn' (arrows). Weigert's elastic-Van Gieson (EVG), × 50 .
Injury to submucosal connective tissue

This is recognised in sections stained with haematoxylin and eosin as apparent clumping of the connective tissue fibres which appear as a more heavily eosinophilic homogeneous mass (Figs. 3, 4) adjacent to a zone of mucosal or submucosal damage. The contrast between damaged and normal connective tissue is accentuated in sections stained by the Weigert's elastic-Van Gieson technique (Fig. 5). This type of lesion is referred to as a connective tissue 'burn'.

\section{Vascular damage}

This is seen in submucosal arteries and arterioles. Acute damage is seen in the tunica media: smooth muscle cells have altered staining characteristics similar to those described above under 'Damage to smooth muscle'. Delayed damage to these vessels is seen as segmental or more extensive fibrinoid necrosis of the tunica media (Fig. 6).

\section{REACTIVE CHANGES}

Epithelial regeneration

This is seen initially as a single layer of flat epithelial cells spreading from the lateral margins of the ulcer across the base of the lesion both in areas of induced ulceration not treated with the laser (Fig. 7) and in treated areas (Fig. 8). The new epithelial cells have large nuclei and plentiful basophilic cytoplasm. In the adjacent surviving mucosa there is usually dilatation of glands which are lined by atypical regenerat-

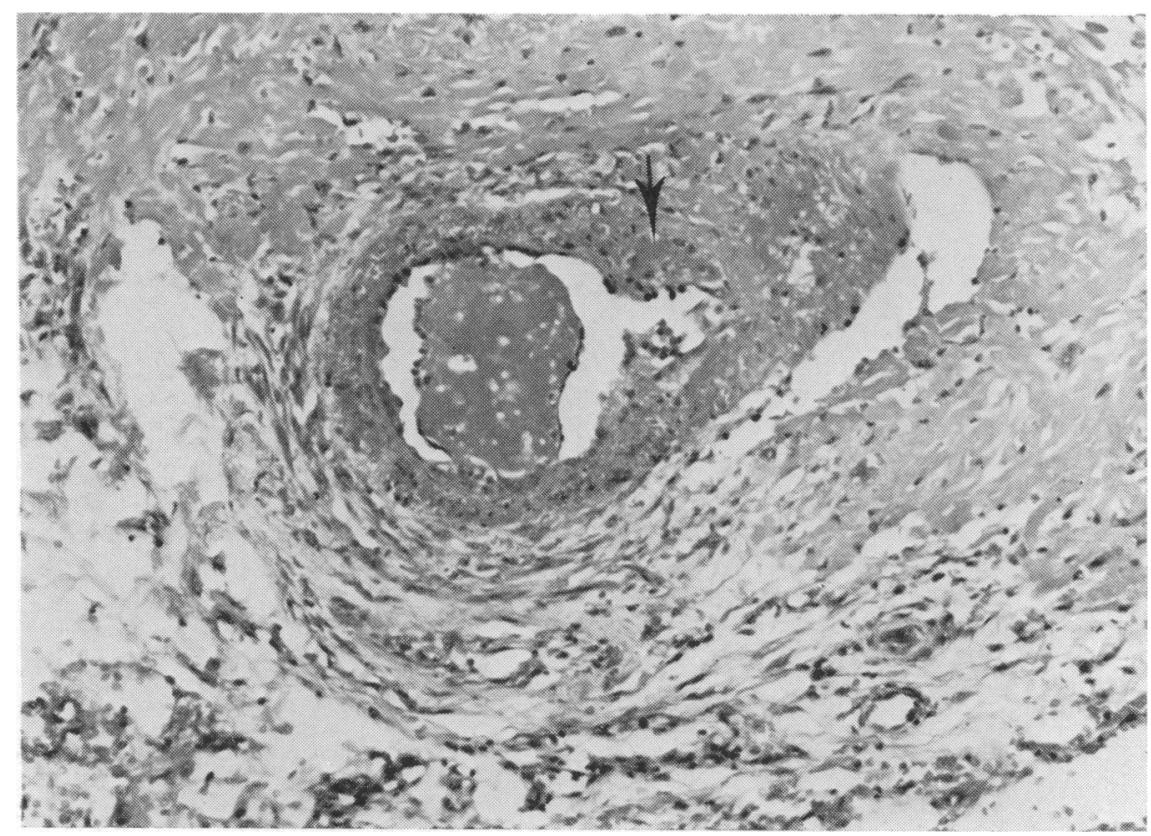

Fig. 6 Seven days after laser injury. $A$ small thrombosed submucosal artery with segmental fibrinoid necrosis of the tunica media (arrow). $H$ and $E, \times 128$. 
Fig. 7 Seven days after induced ulceration (no laser treatment). Regenerating epithelium extends across the ulcer base (arrow). $H$ and $E, \times$ 50 .

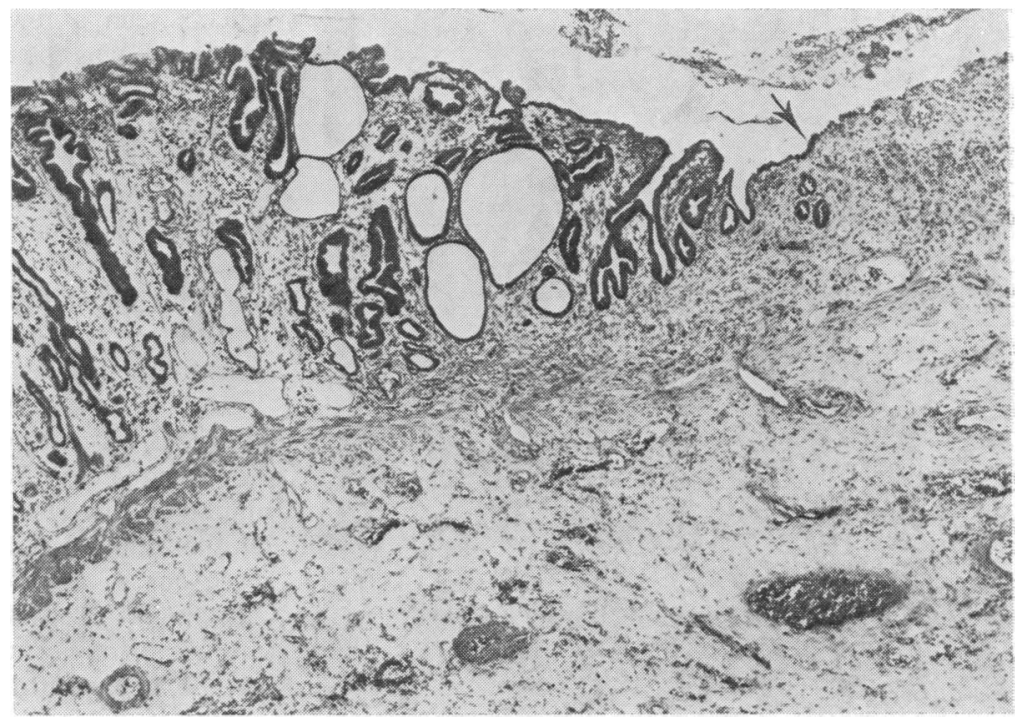

ing epithelial cells. Mitoses are plentiful in these regenerating glands. Extension of the regenerating epithelium continues in a centripetal direction (Fig. 8), so that mucosal integrity is re-established.

\section{Fibrosis}

This results from proliferation of granulation tissue adjacent to injured tissue. Plump fibroblasts with abundant basophilic cytoplasm are clearly distinguishable from the more sparse and slender resting fibrocytes in undamaged connective tissue (Figs. 6,8 ). More mature fibrous tissue contains relatively fewer fibroblasts, a greater proportion of more densely staining collagen, and the vascularity is conspicuously reduced (Fig. 9). New capillaries in granulation tissue are recognised by their plump endothelial cells and the presence of occasional lumina with red blood corpuscles.

\section{Vascular responses}

These include oedema of the connective tissue of the lamina propria or submucosa, extravasation of red blood corpuscles, and infiltration by neutrophilic leucocytes.
Fig. 8 Seven days after laser injury $(12 \mathrm{~W}, 2 \mathrm{~s})$. There is loss of muscularis mucosae with subepithelial fibroblastic proliferations (arrow) and fibrinoid necrosis and thrombosis of submucosal arteries. $\mathrm{H}$ and $E, \times 50$.

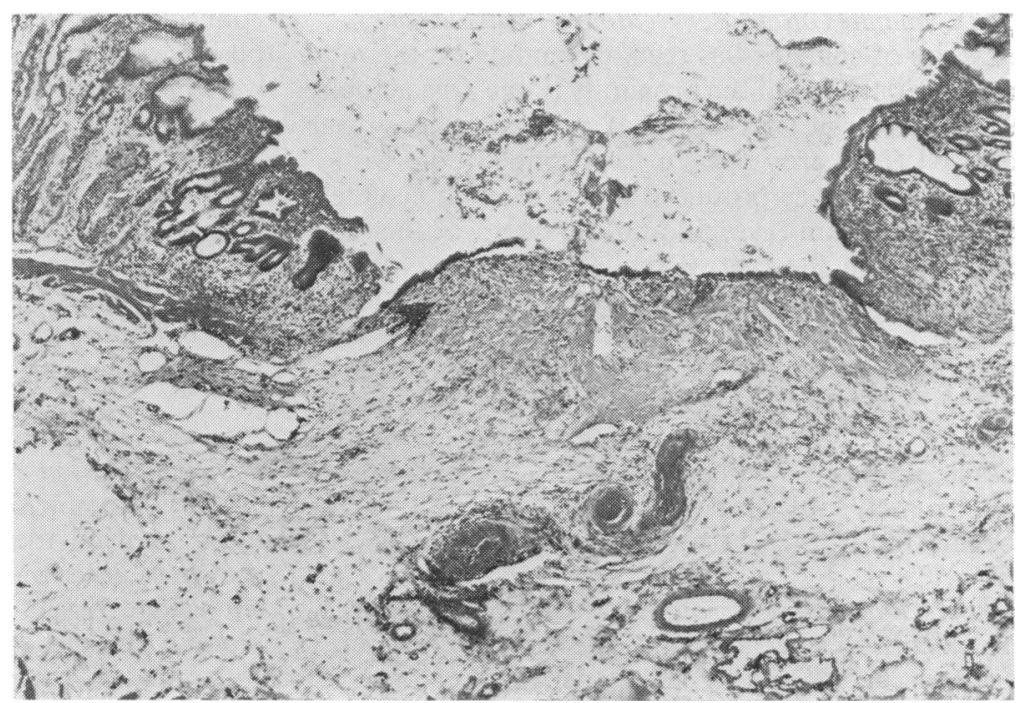




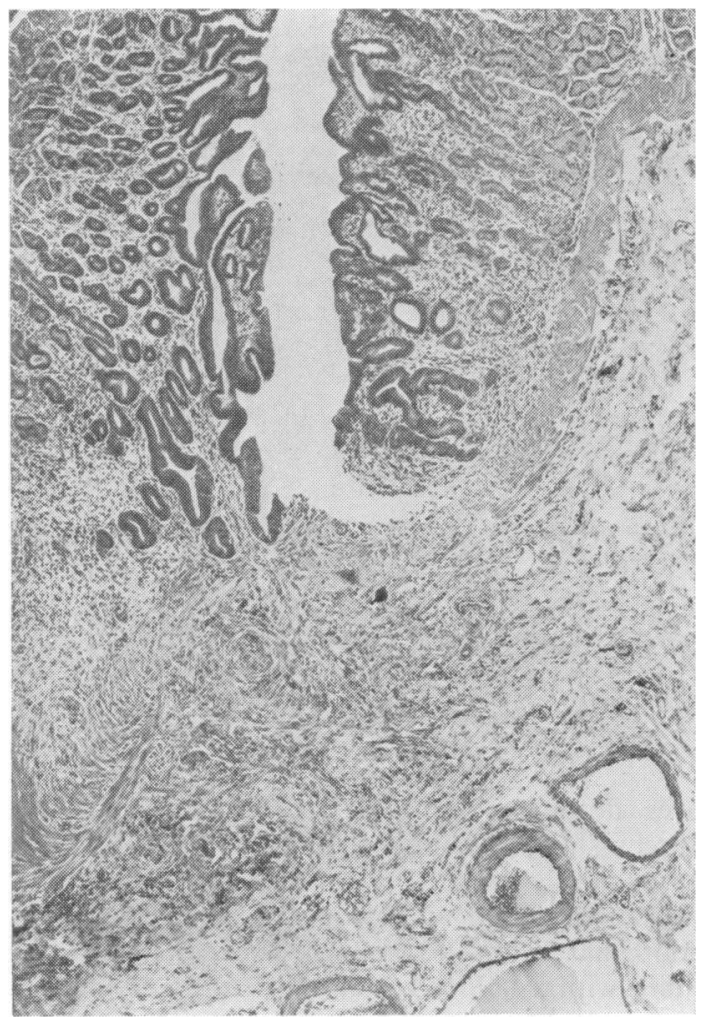

Fig. 9 Seven days after laser injury. Dense fibrous reaction replacing missing muscularis mucosa with atypical regenerating epithelium at the edge showing glandular proliferation and dilatation. $H$ and $E, \times 50$.

\section{OBSER VATIONS ON TREATED MUCOSA} NORMAL MUCOSA

Thirty minutes after laser treatment (acute lesions)

A series of changes was seen, depending on the total energy applied, and the proximity to the area actually exposed to the laser beam. If sufficient energy was applied to destroy cells, a flask-shaped hole with a charred base was produced in the area immediately below the beam (Fig. 5), and the depth of this hole depended on the energy applied. An energy of $50 \mathrm{~J}$ produced serosal damage; in contrast, with $8 \mathrm{~J}$ only a few cells at the surface were killed but there was detachment of the surface epithelium, underlying in situ mucosal damage and damage to the muscularis mucosae and submucosal connective tissue with mild oedema of the lamina propria immediately adjacent to the area exposed to the beam (Fig. 3).

\section{One week after laser treatment}

The depth of effects again depended on the energy applied, and, for the same energy, the depth of effects seen a few minutes after exposure and at one week was the same. Figure 8 shows healing in a hole created seven days earlier with an energy of $24 \mathrm{~J}$. The most striking change seen at this stage was segmental fibrinoid necrosis of small submucosal arteries (a vessel from another similar lesion is shown at higher magnification in Fig. 6). At this stage some of these affected vessels contained thrombi, but these were never seen in acute lesions. Infiltration of neutrophil leucocytes in the connective tissue adjacent to the penetrating laser lesions was a variable feature, but capillary and fibroblastic proliferation were conspicuous in the mucosa and submucosa and were often most obvious around damaged arteries. A thin layer of regenerating epithelium extended from the edges of the ulcer base across the floor of the lesion. The mucosal oedema at the side of acute lesions had resolved after seven days and at this stage there was dilatation of the regenerating adjacent mucosal glands. The extent of the changes is clearly defined by comparing the submucosal arterioles in Fig. 8. Those nearest the mucosa show fibrinoid necrosis and thrombosis, whereas the deeper single arteriole is normal.

MUCOSA IN WHICH STANDARD ULCERS HAVE

BEEN CREATED USING 'THE ULCER MAKER'

These lesions were made in the body and fundus of the stomach of heparinised dogs to give a model of bleeding ulcers to assess the effectiveness of argon laser photocoagulation.

\section{No laser treatment}

At 30 minutes a wide area of ulceration extended to the submucosa. The base of the lesion contained blood and a few neutrophil leucocytes in adjacent connective tissue. Extravasation of red blood corpuscles, oedema, and inflammatory cell infiltration were more marked after seven days and granulation tissue proliferated in the base of the ulcer. Partial epithelialisation of the ulcer base was seen and adjacent glands were dilated and lined by atypical regenerating epithelium (Fig. 7). Examination of the ulcer sites after four weeks revealed no naked-eye abnormality and histological examination revealed only dilatation of occasional gastric glands, implying that healing was almost complete.

\section{Effects immediately after successful laser photocoagulation}

(That is, complete haemostasis was achieved.) The ulcer involved the whole thickness of the mucosa, the muscularis mucosae, and adjacent submucosal connective tissue. There was extravasation of red blood corpuscles and mild oedema in the submucosa. Inflammatory response was limited to margination of 
neutrophil leucocytes in capillaries. Laser effects at this stage consisted of charring of the ulcer surface, in situ damage to adjacent mucosal cells, and connective tissue burn damage in the submucosa adjacent to the base of the ulcer. Within this last zone there were damaged arteries, but none was thrombosed. (Fig. 4).

\section{One week after photocoagulation}

The ulcer extended through the mucosa and muscularis mucosae to involve the inner submucosa; adjacent submucosal connective tissue was oedematous and haemorrhagic. The floor of the ulcer was filled with well-developed granulation tissue. Small submucosal arteries in the edge of the ulcer had fibrinoid necrosis of their tunica media, and some contained organising thrombus. Mucosa adjacent to the ulcer had dilated glands with regenerating epithelium. There was no damage to the external muscle layer.

\section{Two weeks after photocoagulation}

No gross mucosal lesion was found. Histological

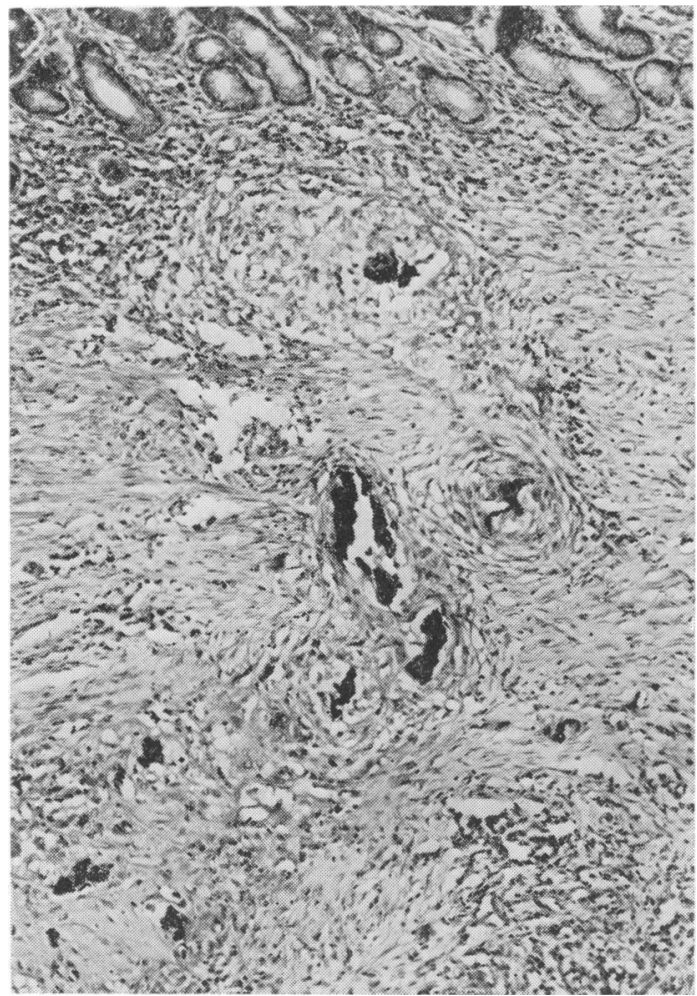

Fig. 10 Laser treatment of induced ulcer ( 28 days). The mucosa is restored, but granulomata and fibrosis are seen around charred tissue fragments in the submucosa. $H$ and $E, \times 128$. examination revealed a regenerating mucosa with occasional dilatation of glands. Epithelial differentiation was not complete. There was some fibrosis between regenerating glands and damaged muscularis mucosae was replaced by scar tissue. In the submucosa there was residual oedema and neutrophil leucocyte infiltration. Fragments of charred tissue in the submucosa were surrounded by macrophages and giant cells.

\section{Four weeks after photocoagulation}

The mucosa was intact, but glands were small with indistinct crypt lumina. The underlying muscularis mucosae was replaced by young fibrous connective tissue. The most striking change was in the underlying submucosa where several fragments of charred tissue were surrounded by a granulomatous reaction of macrophages, giant cells, and fibroblasts (Fig. 10).

\section{Discussion}

These studies have shown a full range of tissue effects caused by the laser treatment, ranging from total destruction of cells and the creation of holes to mild mucosal oedema which resolved completely after one week. Between these two extremes were intermediate changes, seen especially in the submucosa, where arterial necrosis and connective tissue 'burns' lead to an inflammatory cell response and proliferation of granulation tissue. The healing process was essentially complete after four weeks.

To assess the safety of laser photocoagulation, it is necessary to know the extent as well as the nature of the changes produced in the tissue around any treated bleeding point, and how these changes evolve through the healing period. The distribution of changes is clearly illustrated by Fig. 3-the area of affected tissue is hemispherical. At greater energies, when more cells are destroyed and a hole created, the area affected becomes cylindrical in shape, centred around the hole, with a hemispherical 'front' around the base of the hole (Fig. 5). However, as long as the laser beam is aimed at one spot on the tissue, there is a limit to the extent of damage laterally, and measurements on a large number of lesions have shown that this limit is about $1 \mathrm{~mm}$ beyond the edge of the beam. Consequently, the area affected can never be more than $2 \mathrm{~mm}$ wider than the spot size of the laser beam on the tissue. This is due to the high absorption coefficient of gastric tissue for the blue-green argon light, and the same limit applies to the depth of effects below the exposed area. No effects can be produced more than $1 \mathrm{~mm}$ below the exposed surface unless enough energy is applied to actually destroy the overlying cells. 


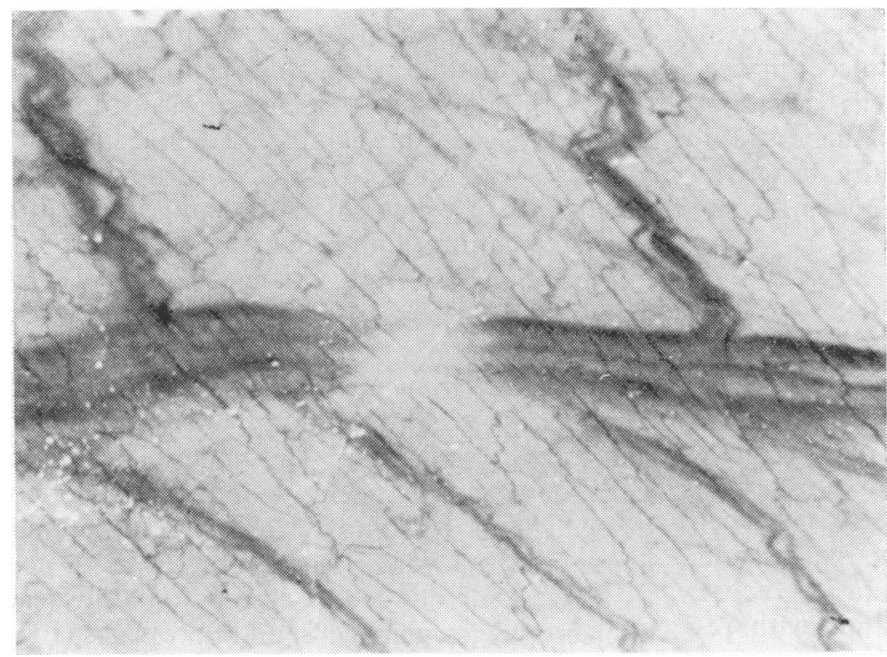

Fig. 11 Thermal contraction of a serosal vein immediately after laser treatment.
The mechanism of haemostasis is thermal contraction of the walls of the bleeding vessel and of the surrounding tissue. Contraction of tissue is seen as the laser treatment is applied in all cases, but this is clearly shown in Fig. 11, in which a serosal vein has shrunk and its lumen has been obliterated after exposure. The absence of thrombi in blood vessels immediately after laser photocoagulation (even in non-heparinised animals) provides morphological evidence that corroborates the physiological interpretation of the haemostatic mechanism. However, there is a limit to the size of vessel that can be sealed by this mechanism. We have carried out pilot studies which suggest that arteries up to about $1 \mathrm{~mm}$ diameter can be closed, but many more experiments are necessary to decide whether the method can be adapted for the treatment of vessels as large as oesophageal varices.

For maximum contraction, it is important to choose the correct rate of deposition of energythat is, the power. If the power is too high, cell destruction may occur under the centre of the beam before the desired thermal contraction can take place over the whole exposed area. In contrast, if the power is too low, the absorbed energy is dissipated over a wide area by thermal conduction and no useful contraction occurs. Our studies ${ }^{1}$ showed the optimum power level to be 7-9 W, although slowly bleeding lesions can be stopped at slightly lower power levels. As shown above, cell destruction in normal mucosa starts with energies of about $8 \mathrm{~J}$; consequently, at a power of $8 \mathrm{~W}$ (the middle of the optimum range), the ideal exposure time is one second, to obtain maximum contraction with minimum damage. This figure has proved a useful guide in practice, although longer exposures can be used when the beam moves across the tissue as the laser is being fired (a common situation at endoscopy in the presence of peristaltic and respiratory movements).

The degenerative changes in the mucosa and submucosa produced by argon laser photocoagulation and the rate of mucosal regeneration, are similar to those described by Waitman et al. ${ }^{2}$ and Le Bodic et $a l^{3}$ although they did not discuss the factors determining the extent of tissue injury. The nature and rate of healing after laser treatment appear to be similar to those described after other forms of injury to the gastric mucosa. ${ }^{6}$ The arterial fibrinoid necrosis appears to be a delayed effect, as it was not seen earlier than one week after laser photocoagulation. It may be of ischaemic origin and could result from the combined effects of reduced luminal flow and impaired diffusion from the vasa vasorum that course through the adventitial connective tissue damaged by laser treatment.

In our study another notable additional feature of the laser lesion when examined after two and four weeks was the submucosal granulomatous reactions around charred tissue fragments (Fig. 10). This chronic inflammatory and fibrosing reaction seems likely to persist beneath the healed site of laser treatment; longer-term study will be necessary to assess the ultimate fate of the granulomata.

We should like to thank Professor G H Arthur and the staff of the School of Veterinary Science, Langford, for their help and advice throughout this project. We should also like to thank Mrs M Maddocks for the histological preparations and $\mathrm{Mr} \mathrm{C} \mathrm{C}$ Jeal for the photography. This work was carried out with the support of a grant from the DHSS. 


\section{References}

'Bown SG, Salmon PR, Kelly DF, et al. Argon laser photocoagulation in the dog stomach. Gut 1979; 20: 680-7.

${ }^{2}$ Waitman AM, Spira I, Chryssanthou CP, Stenger RJ. Fiberoptic-coupled argon laser in the control of experimentally produced gastric bleeding. Gastrointest Endosc 1975; 22: 78-81.

${ }^{3}$ Le Bodic L, Le Bodic MF, Sudry P, LeMort J, Joubert B. Étude des effets hémostatique du lasera Argon sur la paroi gastrique du chien. Ann Anat Pathol (Paris) 1979; 24: 15-28.

${ }^{4}$ Protell RT, Silverstein FE, Piercey JRA, Dennis MB, Sprake W, Rubin C. A reproducible animal model of acute bleeding ulcer-the 'ulcer maker'. Gastroenterology 1976; 71: 961-4.

${ }^{5}$ Drury RAB, Wallington EA. Carletons' histological technique, London: Oxford University Press, 1973.

${ }^{6}$ McMinn RMH. Tissue repair. New York: Academic Press, 1969: 231. 